\title{
The cyborgification of paralympic sport
}

\author{
P. David Howe ${ }^{1, *}$ and Carla Filomena Silva ${ }^{2}$ \\ 1 School of Sport, Exercise and Health Sciences, Loughborough University, Loughborough UKLE11 3JE, England \\ 2 School of Science and Technology, Nottingham trent University, England
}

Received 23 February 2017, Accepted 18 May 2017

\begin{abstract}
Since the turn of the century, the Paralympic movement has gained a high public profile. We will argue that this new high profile is a direct result of the focus of media attention upon new technologies of prosthetic medicine that have helped to create a legion of cyborg bodies that is manifest in the image of the contemporary sporting supercrip. This paper highlights the development of a technocentric ideology that has been embraced within the Paralympic movement. In embracing this ideology, the International Paralympic Committee (IPC) began to celebrate the cyborgification of Paralympic bodies. Ultimately, this paper questions whether the advances in technology are actually empowering all disabled athletes or simply those who have the potential to be cyborgs.
\end{abstract}

Key words: cyborg, cyborgification, disability, Paralympics, supercrip, technology

Résumé - La cyborgification du sport paralympique. Depuis le début du siècle, le mouvement paralympique a acquis un profil grand public. Nous allons faire valoir, qu'il résulte directement de l'attention médiatique portée aux nouvelles technologies de la prothétique qui ont contribué à créer une légion de corps cyborg qui se manifeste à l'image du supermarché sportif contemporain. Cet article souligne le développement d'une idéologie technocentrique qui a été adoptée dans le mouvement paralympique. En adoptant cette idéologie, le Comité international paralympique (IPC) a commencé à célébrer la cyborgification des organes paralympiques. En fin de compte, cet article se demande si les progrès de la technologie habilitent actuellement tous les athlètes handicapés ou simplement ceux qui ont le potentiel d'être cyborgs.

Mots clés : cyborg, cyborgification, invalidité, paralympique, supermarché, technologie

As we write this paper, there is debate surrounding whether a Germany long jumper Markus Rehm, who is an amputee, should be allowed to compete in the Rio 2016 Olympic Games (Tuscher, 2016). Rehm who lost his lower right leg in a boating accident at the age of fourteen has a personal best in the long jump that would have won the Olympic gold medal at London 2012. He is a real contender for a medal in Rio 2016 but controversy surrounds him as he jumps off his prosthetic leg and his performances have improved greatly since he changed his take-off leg from his human one. Many in the sport of athletics feel he has an unfair advantage but these issues of eligibility are not new. Issues concerning eligibility for elite sporting contests may have never been more debated than when South African $400 \mathrm{~m}$ runner, Oscar Pistorius, decided that he was searching for a new challenge (Howe, 2011). Unlike Rehm, Pistorius is a bi-lateral below the knee amputee who came to the attention of those interested in Paralympic sport

*Corresponding author: p.d.howe@lboro.ac.uk following his success in the Athens 2004 Paralympic Games. In that event, Pistorius destroyed the field in the $200 \mathrm{~m}$, setting a new world record in a race that included athletes that were uni-lateral below the knee amputee and considered to be less impaired than him. Pistorius went on to compete in the Olympic Games in 2012 to much fanfare (Kelso, 2012) and became celebrated for his achievements on the mainstream sporting stage. It was clear that Pistorius was a unique athlete, not only for his physical achievements but also because an absence of lower limbs required the adoption of two prosthetic limbs that have literally catapulted him beyond the horizon of the Paralympic movement. Athletes such as Rehm and Pistorius who have amputated lower limbs often run on carbon fibre 'blades' that act in a similar fashion to feet. As a result, Pistorius has been famously referred to as the Blade Runner (Hunt-Grubbe, 2007; Morrissey, 2008; Swartz \& Watermayer, 2008) and Rehm more recently the Blade Jumper (Hudson, 2016). The utilisation of such technology by Paralympic athletes means that they can be 
conceptualised as the embodiment of Haraway's (1991) cyborg that is a hybrid body resulting from fusion of a live organism and man-made technology. It is the Paralympian cyborg, rather than Pistorius and Rehm, which is central to the argument that follows.

In the context of Paralympic sport, the most successful cyborg athletes may be seen as 'supercrips' (Howe, 2011; Silva \& Howe 2012). Following Berger, supercrips "are those individuals whose inspirational stories of courage, dedication, and hard work prove that it can be done, that one can defy the odds and accomplish the impossible." (Berger, 2008: p. 648). It also has been argued that the label of supercrip can be negatively bestowed upon impaired individuals who simply manage to live 'an ordinary' life (Kama, 2004). Specifically in the context of Paralympic sport and for the purpose of this paper, the supercrip is the athlete who wins and is celebrated with relatively high profile media exposure. Those athletes who win but do not receive recognition in mainstream media are not supercrip in the context of the Paralympics as they are often marginalised by the degree or nature of their impairment (Howe, 2011; Howe \& Jones, 2006). Important in this paper is whether or not athletes use mobility technologies and, by extension, the degree to which they are cyborgs. The process of making a cyborg, we articulate as cyborgification (Howe, 2011) as it is useful to understand that in the contemporary world all our bodies some way use technology. Our bodies can be placed along a continuum from those that require very little technological aid to those whose lives benefit from a great deal from technology. Paralympian wheelchair racers and prosthetic wearing athletes are the most explicit examples of cyborgification in sport today and it is these bodies upon which the Paralympic movement has been increasing celebrated (Howe \& Parker, 2012).

This paper will explore the issues of cyborgification and the supercrip, and how the embodiment of the cyborg body has led to the contemporary manifestation of the supercrip. To begin, the paper will briefly highlight the central importance of a key element of Paralympic culture, classification and how this accentuates different forms of impairment that relate in very particular ways to mobility technologies. As such, throughout the paper I will refer directly to these impairment forms as this is standard practice within Paralympic culture. ${ }^{1}$ Following this, the paper will explore what Charles (1998) has called technocratc ideology, that is the importance society places upon technology and the role this plays in shaping western ways of thinking. As a result of the influence of technology certain impaired bodies of athletes may be seen as a product of cyborgification, that ultimately leads to the successful competitors being seen as supercrips (Berger, $2004,2008)$. Bodies that are the product of cyborgification, so it will be argued, are the vanguard of the sport for the disabled and as such they are celebrated far more than

\footnotetext{
${ }^{1}$ We are aware that this approach is not favoured in social scientific circles but it is important here to accurately reflect Paralympic culture.
}

those competitors that do not use mobility technologies. The paper will conclude by asking whether the advances in technology are actually empowering disabled athletes.

\section{Paralympic culture and classification}

The International Paralympic Committee (IPC) currently organises and administers both the Paralympic Games and the Quadrennial World Championships for individual Paralympic sports such as athletics. Using the resources of the International Organisations of Sport for the Disabled (IOSD) (Jones \& Howe, 2005) ${ }^{2}$ (including athletes, volunteer administrators, and classification systems), the IPC has made the Paralympic Games into the most recognisable and influential vehicle for the promotion of disability sport.

Classification is central to the structuring of competition in Paralympic sport, similar to the systems used in the sports of judo and boxing where competitors perform in distinctive weight categories (Howe \& Jones, 2006; Jones $\&$ Howe, 2005). Within the Paralympics competitors are classified by their body's degree of function within their chosen sport. Classification takes the form of a series of functional tests that determine the appropriate category in which to place the athlete so that equitable sporting contests can be achieved (Sherrill, 1999) and as such is a fundamental component of Paralympic culture (Howe 2007,2008 a). It is a process that is conducted by a group of qualified classifiers who have between them an expertise in physical impairments and the sporting practice in which they are classifying athletes. The classification process used by the IOSDs is a form of selective classification (Tweedy \& Vanlandewijick, 2009) that makes a distinction between the physical potential of athletes. The successful athletes in each class should have an equal chance of accumulating physical capital (Jones \& Howe 2005). In reality, however, there are a number of factors that impact upon the accumulation of capital (both physical and cultural) in various classifications the most salient of which for the purpose of this paper is whether or not the athlete uses mobility technologies while they perform (Howe, 2011). For example, the wheelchair is the ubiquitous symbol for disability. The ever-present iconography of the wheelchair in disabled parking bays, for example, means that the public can relate easily to this mobility technology in the context of Paralympic sport. There has also been research to suggest that within

\footnotetext{
${ }^{2}$ The federations, namely the Cerebral Palsy International Sport and Recreation Association (CP-ISRA), International Blind Sport Association (IBSA), International Sports Federation for Persons with Intellectual Disability (INAS-FID), and, the International Wheelchair and Amputee Sport Association (IWAS). This is a federation that was launched in September 2004 at the Athens Paralympic Games. It is the result of a merger of two federations, the International Stoke Mandeville Wheelchair Sports Federation (ISMWSF) and the International Sport Organisation for the Disabled (ISOD), that have been part of the IPC since its inception.
} 
Paralympic sport there is a hierarchy of 'acceptable' impairment within the community of athletes (Sherrill \& Williams, 1996; Schell \& Rodriguez, 2001). As a result, it reinforces the position of wheelchair athletes on the top of a hierarchy of disabilities that locates the less socially acceptable disability categories as marginal (Kama, 2004; Haller, 2000; Mastro, Burton, Rosendahl, \& Sherrill, 1996).

The original classification system that was developed by the International Wheelchair and Amputee Sport Association (IWAS) can be understood as a major reason why wheelchair athletes are celebrated ahead of athletes from other impairment groups. This system classified athletes with spinal cord injuries according to where the lesion was in their spine because back function is of great importance in sport. It was believed that athletes with a greater level of function in their spine should be in a different class from those athletes that have less. Athletes who were leg amputees could easily be fitted into the most able class in this system as they had full use of the spine. It was the IWAS system that was at the heart of the establishment of the Paralympic movement and which all other impairment groups had to petition to join in the early days of the movement. As an increasing number of athletes with different impairments aspired to get involved in sport for the disabled, IWAS established a broad class known as les autres. ${ }^{3}$ Some les autres athletes that use wheelchairs, including those with spina bifida and polio, were able to be slotted into the IWAS system, but it was and never has been an exact science. However, many les autres were ineligible because they did not need to use a wheelchair and this ineligibility eventually led to the development of the remaining IOSDs and, ultimately, the development of the IPC. In this way, the classification system that led to the development of sport for the disabled was not political or culturally neutral. In other words, the systems of classification developed and adopted within the cultural context of Paralympic sport are the product of the history of this practice. When the technology for lower leg prosthesis developed to such a degree that it became relatively comfortable to do sport with specifically developed sporting prosthesis, many of the bodies classified into wheelchair sports became standing athletes (Howe, 2008a, 2011). As a result, the history of the Paralympic movement places athletes in wheelchairs and those with lower leg prosthesis at its centre in part because athletes with spinal cord injuries and amputations were the first to compete in disability sport (Howe, 2008a).

\footnotetext{
${ }^{3}$ Les autres is a French phrase used within disability sport circles meaning 'the others'. Originally, the term refers to athletes with a disability who did not directly fit into the classification system established by IWAS. Today, les autres is used to highlight any athlete who is not specifically referred to in the classification systems of the IOSDs and that is able to be slotted into an existing classification system. I use the term here specifically to refer to athletes with a disability who do not use either a wheelchair or prosthesis while competing in athletics.
}

Since 1988, there has been a marked improvement in the technology, particularly in western nations, associated with leg prosthetics. The materials from which prostheses are made have changed markedly from wood to fibreglass to all manner of carbon fibre and lightweight metals used in advanced scientific design (Howe, 2008a). These mobility aids have been a product of state of the art technologies and as a result the athletes who are the vanguards of the deployment of this new technology are producing performances that would have been considered impossible twenty years ago. It can be argued that this sporting technology has advanced with three aims in mind: to produce better performances; to increase the comfort for an individual, athlete or otherwise; and to enable an improvement in efficiency of movement. Advancement is most evident on the track, but also in field events where athletes with amputations have the option of competing as standing athletes or as athletes who use throwing frames (Howe, 2008, 2011). Traditionally, a large percentage of track and field athletes with full or partial leg amputations have for reasons of comfort competed from a wheelchair. The use of flex-foot technology that is used instead of the old fashioned prosthesis, where flexion of the ankle was either mechanical or non-existent, is universal at the highest level of Paralympic sport. It is this technology that has quite literally catapulted Pistorius and Rehm to be the public face of the contemporary Paralympic movement. The advances in technologies of both prosthetic limbs and wheelchairs allow these movement technologies to become productive extensions of their bodies. These athletes are all individuals who are accustomed to using these technologies for mobility, to the degree that moving becomes habitual, and allows them to develop a hybrid body (Haraway, 1991: p. 178). In the case of sport, both artificial limbs and wheelchairs can be seen as a form of prosthesis. The term prosthesis is Greek for an addition designed to remove physical stigma.

Prosthetic medicine is dedicated to physical normalisation and is devoted to the artificial alteration of both function and appearance, but it enters the realm of biopolitics because it uses the 'normal' body as its tribunal and blueprint for action, and treats the impaired body as a spoilt entity that must be hidden and corrected (Hughes, 2000: p. 561).

There is a desire to 'create' the normal and at the same time allow individuals to be more mobile and therefore independent. In the context of sports participation as well as day-to-day mobility, one of the problems associated with traditional technology is the development of pressure ulcers and painful stumps that develop where the prosthesis joins the body (Rossi, 1974; DesGroseillers, Desjardins, Germain, \& Krol, 1978) but as these technologies advance, these medical ailments become less commonplace. The treatment of the nexus between the prosthesis and the body has developed at pace with the actual replacement limb. Today, the top of the range 'flex foot' legs are built around the individual's stump and are 
secured in place by a vacuum seal device which often includes gel padding which greatly reduces the risk of injury from swelling and friction (Howe, 2006, 2011). We now turned to the notion that such developments and their celebration (Howe \& Parker, 2012) signal a 'technocratic ideology' that Shogun (1998) has suggested is becoming increasingly pervasive within the Paralympic movement.

\section{Technocratic ideology as manifest in Paralympic sport}

The technological innovations discussed in the two preceding sections are important factors in helping to focus the Paralympic spotlight on athletes that are members of IWAS. It is important however to remember that these technologies have to be purchased and therefore the Paralympic movement represents a developing market for the sale of technologically advanced mobility aids. As such, many of the most up-to-date mobility technologies highlighted in this paper are inaccessible to athletes from much of the 'developing' world where the population is generally poorer. In this sense, Paralympic athletics may be seen as technologically advanced on the one hand, but isolationist and exclusionary on the other. In other words, the importance of technology in the context of Paralympic track and field athletics can best be expressed in the phrase 'technocentric ideology' (Charles, 1998: p. 379).

The move to hi-tech mobility devices specifically designed for sport is a response the general push for more technological advancement in society but it also relates to the desires of the athletes to perform with greater proficiency. Today, many of the elite athletes work with leading wheelchair and prosthesis suppliers to ensure their future success is based on the technologies they use as much as it is the training regimes they follow. As a result, the top cyborg athletes also receive commercial reward for their involvement in the development and manufacture of state-of-the-art technology that is at the heart of technocratic ideology. In other words, technology is literally pushing the Paralympic Movement. As Charles suggests:

Technology and kinesiology are symbiotically linked. They have a mutually beneficial relationship. As technology advances, so does the quality of scientific research and information accessible in the field. As kinesiology progresses and gains academic acceptance and credibility, technology assumes a more central role in our field. The more scientific the subdiscipline, the more we can see technology at play (Charles, 1998: p. 379).

Following this statement, it is clear that the field of high performance sport (of which Paralympic sport is a subset) has benefited from an increase in technologies that have been developed to harness the power of the human

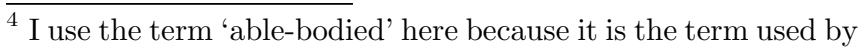
athletes within the cultural context of the Paralympic.
}

body (Burkett, 2010; Davis \& Cooper, 1999). Able-bodied ${ }^{4}$ high performance athletes rely on technology in their dayto-day training (Hoberman, 1992; Shogun, 1998), yet when these athletes perform in sports like track and field athletics, the technology that has allowed them to train and compete in the sporting arena may be completely obscured from view. An able-bodied athlete does take technology with him or her to the start of an Olympic final as their clothing and footwear are products of advanced technology. In fact, Butryn (2002, 2003) has highlighted that high performance (able bodied) track and field athletics is surrounded by technologies that enable athletes to become cyborgs. However, specialist clothing and shoes appear less like advanced technology in comparison to racing wheelchairs and prosthetic limbs, that lead to the cyborgification of bodies, as they are not explicitly aids for mobility. As Shogun suggests:

When persons with disabilities use technologies to adjust the participation in "normal" physical activity, the use of these technologies constructs this person as unnatural in contrast to a natural, nondisabled participant, even though both nondisabled participants and those with disabilities utilize technologies to participate (Shogun, 1998: p. 272).

Technologies such as racing wheelchairs and flex-feet (artificial legs biomechanically designed for running) have enhanced the performances of athletes whose impairments benefit from their use and are central to the identity of the Paralympic movement. It is these cyborg sporting bodies that are most often celebrated by the IPC (Howe, 2007, 2008a, 2011). Bodies that are able to successfully adapt to technology that wherever possible normalises their movements within society generally and on the athletics track specifically are seen as (the most) successful. According to Seymour:

A winning wheelchair athlete is seen as the epitome of rehabilitative success. The vision of strong male bodies competing for honours on the sports field is an image that has currency in the able-bodied world. Bravery in overcoming the catastrophe of a damaged body is a quality everyone can admire (Seymour, 1998: p. 119).

This image extends to amputee athletes who have also suffered traumatic injuries and use performanceenhancing prosthetic limbs. The use of mobility technologies provides an opportunity for the user of reembodiment (Seymour, 1998) that is not available to individuals who are congenitally impaired. That is users of both wheelchairs and prosthetic limbs that have acquired their impairment are able to establish a distinctive identity with their new cyborg bodies. These bodies are the hallmark of IWAS and central to the public understanding of the Paralympic movement. One explanation for this may be the fact that these athletes more than any others expose the ability in disability sport. Elite wheelchair racers over distances longer than $800 \mathrm{~m}$ are considerably faster than able-bodied runners 
and those athletes who wear hi-tech prostheses have higher visibility associated with their performances than ambulant athletes with cerebral palsy and visual impairment.

\section{The importance of (re-embodiment)}

How as an athlete with a particular impairment at one time become a high profile cyborg that is celebrated within the Paralympic movement? It might be argued that starting point is Merleau-Ponty's conceptualisation of embodiment 'a grouping of lived-through meanings, which moves towards its equilibrium' (Merleau-Ponty, 1962: p. 288). Merleau-Ponty sought to reject the dichotomization and fragmentation of Western scientific thought which broke down reality into zones of mutual exclusivity; nature/nurture, body/soul, subject/object, etc. (Iwakuma, 2002). Here, we follow Csordas who suggests that embodiment is "an indeterminate methodological field defined by perceptual experience and mode of presence and engagement in the world" (Csordas, 1994: p.12). From this point of view, inanimate and human made objects can become incorporated into a person's body image, such as a visually impaired person using a cane to move through spaces without relying on visual data (Iwakuma, 2002: p. 79). Furthermore, objects can become an integral part of someone's identity, something which is illuminated by "people's peculiarities, obsessions and mixed feelings towards their aids [which] cannot be explained satisfactorily if they are seen as mere instruments" (Iwakuma, 2002: p. 79). This can clearly be seen in the attachment that some athletes have to their mobility aids/sporting equipment (Howe, 2008a, 2011).

For Iwakuma, 'embodiment cannot be complete as long as $\mathrm{s} / \mathrm{he}$ is conscious of, for example, pushing a wheelchair for transportation or is making an effort to flip a page while using prosthetic arm' (Iwakuma, 2002: p. 81). Getting reoriented with an impaired body is what Wendy Seymour's notion of re-embodiment, where her informants reproduced conventional forms of masculinity and femininity, using these conventions as a guide for reembodiment, though she posits that over time the experience of having a body seen as abnormal may lead to being less tied to the male-female dichotomy (Seymour, 1998: p. 36-37).

The issue of embodiment naturally leads to discussions of technology and the role it plays in people's sporting lives. Jönsson (2010) writes about the elimination of gender inequalities in sport through technological advancement. He argues that it is difficult to separate the athlete from the athletic performance since "the athlete's bodies and skills are integrated into the same body of performance" [original emphasis] (Jönsson, 2010: p. 252). The second distinction he seeks to contradict is between bodies and sport technologies, writing that, "placed in a certain sports environment, the body can be seen as sport technology in itself" (Jönsson, 2010: p. 252). He gives the example of Formula One racing, in which the winner of a race is announced as both the name of the driver and the company that built the car, despite the fact that during the race the two entities are interdependent and "blurred at the edges" (Jönsson, 2010: p. 253). We can compare this to wheelchair racing or amputee sprinting and jumping. This difficulty in drawing a distinct line between human and technology lends credence to Haraway (1991)'s cyborg theory. While Jönsson (2010) believes that technology should allow us to, at some point in the future, eliminate identity as a means of separating athletes in competition his call for "a radical cyborg argument for 'real' equality" (Jönsson, 2010: p. 256). The argument that Jönsson proposes is related to the elimination of gender inequalities in the practice of sport, however, we think it can lend credence to the inclusion of protheetic wearing track and field athletes such as Pistorius and Rehm.

Haraway writes that her cyborg theory is 'about transgressed boundaries, potent fusions, and dangerous possibilities' (Haraway, 1991: p. 154) and that 'a cyborg world might be about lived social and bodily realities in which people are not afraid of permanently partial identities and contradictory standpoint' (Haraway, 1991: p. 154). She sees the image of the cyborg as a means of overcoming divisions between people. There is a certain irony to this when we turn to examine the cyborgization of the Paralympic Games, in which the body policing typical of mainstream high performance sport has been reversed and technological innovation has been embraced and celebrated (Howe, 2011: p. 19-20). The lead author has suggested that because the mobility technology used in the Paralympic Games is on the cutting edge, athletes from developing nations are less able to compete, making the Games, to a certain degree, "isolationist and exclusionary" (Howe, 2011: p. 13), which is opposed to Haraway's vision regarding transgressing the boundaries between us and them. It is possible that within the First World's increasing acceptance of, and reliance on, technology lie the seeds of a potentially dystopic future in which the divide between rich nations and poor ones is even greater than it is today and the celebration of cyborg bodies becomes accelerated within the Paralympic movement.

Studies of Paralympic sport must be approached differently than studies of mainstream sport for the simple reason that Paralympic sport is significantly different, as a realm of activity, from mainstream sport. One expression of this difference can be found by examining sports requiring mobility aids, in which studies have shown that performance is influenced by three factors: the athlete themselves, the mobility aid (such as a wheelchair or prosthetic limb) itself, and the interface between the two (Keogh, 2011). In his evaluation of several scientific studies evaluating performance across a range of sports, Keogh suggests that "while there are many similarities in the biomechanics of Paralympic and Olympic athletes, there are also many differences" (Keogh, 2011: p. 249) and that further research is needed to fill "gaps in the literature" (Keogh, 2011: p. 249).

Putting aside the purely scientific reasons behind it being worthy of careful attention, Paralympic sport deserves theoretical consideration separate from other 
sports activities because of the identities of the participants. Robert Murphy, the anthropologist who slowly became paralyzed as a tumour grew on his spine, wrote that he could feel his social standing change as he became disabled: "A serious disability inundates all other claims to social standing, relegating to secondary stus all the attainments of life, all other social roles, even sexuality. It is not a role; it is an identity, a dominant characteristic to which all social roles must be adjusted" (Murphy, 1990: p. 106). Paralympic athletes can never simply be athletes; they are always 'disabled' athletes and this identity marker remains attached to them throughout their lives, both inside and outside the boundaries of competition:

Success in disabled sport, unlike success in able-bodied sport, is not associated with mastery in other dimensions of life. Achievement in wheelchair sport does not have the power to transform the primary status, that of patient. Disabled sport remains sport for people with damaged bodies. The treatment of the Paralympics by people associated with the regular Olympics is instructive in this regard. It may be 'just as competitive as any other sport', as David claims, but the competition is seen as particular, and the social rewards remain circumscribed within this particularity (Seymour, 1998: p. 115).

In other words, because of the way that disability is viewed in wider society the accumulation of capital, both physical and cultural, is possible through participation in the Paralympic Games, but only to a certain extent and for a particular kind of body. Capital accumulation in the Paralympic Games and how it is affected by the impaired body one possesses can be seen as 'a component of the habitus of elite sport for the disabled illuminates a hierarchy of 'acceptable' impairment within the community of athletes ... as well as mainstream society' (Howe, 2008b: p. 504). In her study of people who had recently suffered a spinal cord injury and their experiences going through the rehabilitation process, Seymour notes that the participants in her study did not fully conform to conventional social categories and because of this many of them were able to "reflect on the nature of their embodied selves, often for the first time" (Seymour, 1998: p. 178). Ironically, their loss of bodily control resulted in a lessening of social control and an opportunity to engage with their bodies in a "new and immediate form" (Seymour, 1998: p. 178).

Of course, many social conventions do still have an influence over people with impairments; they do not live their lives in isolation. Unfortunately, ideals of masculinity and femininity conspire against women in rehabilitation and make their task more difficult (Seymour, 1998). Because men are more likely to suffer spinal injuries they outnumber women in those rehabilitation centres, and the culture of rehabilitation is "dominated by masculine ideas and values ... and rehabilitation projections reflect fixed and static views of men's and women's roles" (Seymour, 1998: p. 113). This is culturally significant to the Paralympic movement as women with impairments are less likely to engage in the practice of sport because of these barriers (DePauw, 1997). Social conventions constantly classify people according to several different factors, but unfortunately the classification someone is given, or that they feel they need to embody, can directly contradict other aspects of that person's life, which may be necessary for their sanity, independence or even survival. This clearly has resonance not just for those people who are impaired but for athletes inside the Paralympic movement as well (Howe, 2008; Howe \& Jones 2006).

\section{Just a body}

The bodies that are celebrated within the Paralympic movement - highly functioning wheelchair racers (Howe \& Parker, 2012) or those who use technologically advanced prosthetics (Howe, 2011) have increasingly high profile because of the ability of the technology they use to enhance their normality. Those bodies that do not use movement technologies to compete in disability sport benefit from advances in sport science support, such as biomechanical and physiological analysis but are still marginalized. For the visually impaired, ambulant cerebral palsy and those with intellectual impairments that are able to compete in sport without the use of special technologies of mobility, there relative normality can be seen as detrimental to how these groups may be treated both inside and outside the Paralympic movement. Athletes with visual impairment are relatively easily understood by the public. A high percentage of the world's population use either spectacles or contact lenses, which are designed to help us better, read the world around us. As our eyesight deteriorates as a result of spending too much time at the computer or through the passage of time and old age, we can understand and appreciate the difficulties associated with poor sight. As a result, athletes with visual impairment are not treated as marginal in western society to the same extent as those who have cerebral palsy or an intellectual impairment (Sherrill \& Williams, 1996).

Neurological impairment is more difficult to understand than others, such as the uncontrollable spasticity of an individual with cerebral palsy or for those where the manifestation of their condition is only evident in social environments such as an athlete with an intellectual disability. Mobility technological intervention has a minimal role to play in managing these types of bodies to a norm that is acceptable to mainstream sporting practices. As such, it is often rather difficult for the general public to see ability in some of the performances of individuals with impairments. In referring to athletes with cerebral palsy a former president of Cerebral Palsy International Sport and Recreation Association (CP-ISRA), Colin Rains stated:

It's tough to say but I believe people think that athletes with cerebral palsy are not totally media friendly, visually. They can be slightly uncoordinated both in their running and their visual expressions. It is possible people find this off-putting (Mott, 2000).

Following Shogun (1998), it could be argued that the mobility technology used in sport for the disabled is unnatural because it is seen as making athletes less 
than human. In fact, in the lead up to the London 2012 Paralympic Games, a television station in the United Kingdom ran an awareness campaign entitled 'Freaks of Nature' (Silva \& Howe, 2012). This campaign was designed to highlight 'supercrip' in Paralympic sports but it did not translate well. For those bodies who are explicitly cyborgs, the 'super human' results achieved through the use of either state of the art wheelchairs or prosthetic limbs, within Paralympic track and field athletics, they have become the new norm or accepted currency over the last two decades within the public understanding of ability within disability sport. Mobility technology allows for exceptional sporting performances in the sport of athletics that to some extent are celebrated by the able-bodied public but such performances are unlikely to be achieved by athletes who compete without these mobility aids. This use of what Butryn (2003) coined 'implement technology' has made the Paralympic Games into a significant sporting spectacle.

The use of these technologies has led to a litany of supercrip stories. As highlighted earlier, the supercrip can leave the observer with the sense of impossible achievement. According to Berger:

'Supercrips' are those individuals whose inspirational stories of courage and dedication, and hard work prove that it can be done, that one can defy the odds and accomplish the impossible. The concern is that these stories of success will foster unrealistic expectations about what people with disabilities can achieve, what they should be able to achieve if only they tried hard enough. Society does not need to change. It is the myth of the self-made man (Berger, 2004: p. 798).

By and large, these narratives follow closely athletes who benefit from technological aids as it is 'easier' to see ability in a fast sprinter on blades like Pistorius or long jumper who springs off a blade to better world class able bodied jumpers. However, many Paralympians who are highly trained and motivated athletes but do not require these technologies therefore can never live up to these ideals which appears imperative in the commercialised world of the twenty first century Paralympic Games. More recent work by Berger highlights the role model capacity of the supercrip and clearly indicates that celebrated athletes are more than a media construction and can act as 'real' mentors (Berger, 2008). While this is a useful point Berger's research is conducted within the context of wheelchair basketball, a sport where high performance technology is also clearly evident (Berger, 2004, 2008) and the players that he cites as role models are clearly a product of a sport that as a whole has gone through the process of cyborgfication.

\section{Discussion}

At the outset of this paper, we asked whether or not an increased emphasis on technology that leads to the cyborgification of the Paralympic Games, and the media spotlight it engenders, leads to the empowerment of the athletes with impairments. In an increasingly commercial world, the technocratic ideology (Charles, 1998) that surrounds track and field athletics at the Paralympics will be hard to transform. The athletes who use wheelchairs and prosthesis are at the centre of the Paralympic movement and will be better consumers simply because they have specialist materials to purchase if they wish to compete at the highest level. The body policing (Cole, $1993,1998)$ that goes on in mainstream high performance sport between what is acceptably human and what is not in the Paralympic world has been, paradoxically, reversed. Oscar Pistorius and more recently Markus Rehm are cases worth considering. When Pistorius originally tried to compete in the Olympic arena, his cyborg body was seen as not human enough (Hunt-Grubbe, 2007; Morrissey, 2008; Swartz \& Watermayer, 2008) yet in the Paralympic world this body is the most highly celebrated. The case for Rehm is still ongoing but by switching his 'takeoff leg' in the long jump, he has created a dilemma for Olympic officials.

It appears that in Paralympic track and field athletics, the closer a body is to a cyborg the more capital it holds which is the opposite to the world articulated by Harraway (1991) in relation to the boundaries between humans and non-humans. Wheelchair users and amputees who use prostheses are tied explicitly to sport technologies and therefore blur the lines between 'natural' and 'artificial' and are perhaps the best example of the cyborg in contemporary society. Butryn see the nexus between the natural and legal and the artificial and illegal as hegemonic humanness (Butryn, 2003: p. 28). Hegemonic humanism can be seen to have been practiced when Oscar Pistorius was initially excluded from competing in able-bodied athletics (Howe, 2008a, 2011). The restoration of his right to compete on his prosthesises was restored because he has no other option but to run on man-made legs and by the fact they were not advantaging him in the context of competition. In a sense, Paralympic sport celebrates 'transgressing the taboo boundary between blood, sweat, and tears, and blood, sweat and gears' (Butryn, 2003: p. 28). Here the cyborg wheelchair user and the prosthetic limb wearer are the role models and supercrips the Paralympic movement triumphs, in a way that Olympic and other mainstream sport has failed to achieve. This is largely because the Paralympics Games was designed to celebrate difference that is distinct from the able-bodied norm. Yet today it appears that Paralympic difference must increasingly take on a cyborg form.

Where does this leave les autres? They certainly have a part to play in the Paralympic movement, but the more marginal the physicality of the body, the further away it is from the potential of cyborgification and the more likely a tragic rather than a heroic allegory will follow them. This analysis tells us a great deal about the politics of disablement. While it is considered an infringement for the able to become too cyborg, for the disabled it is highly advantageous because technology can normalise their 'inferior' bodies to the point where in the case of elite wheelchair racers they can produce super-human results. 
Of course there is a tension here. MacIntyre (1999) tells us that vulnerability and affliction and the related facts of dependence are central to the human condition. The susceptibility to injury and misery, distress and pain is likely to befall us all at some point in our existence. We all will be reliant on others from time to time. It begs the question why impaired bodies are so harshly disabled by society and, at least in the context of Paralympic sport, only those that are cyborgs are celebrated at length. Of these cyborgs, the winners are held up on a pedestal as supercrips.

\section{Conclusion}

In the last twenty years, the associated development of biomechanically and ergonomically responsive prostheses has meant that many athletes who in the past would have competed from a wheelchair are now able to compete from a standing position. While the development of mobility technology that enhances sport performance is understandably beneficial for those who can go through the process of cyborgification, it marginalises further those athletes that do not use technologies directly in their competitive performance. Because the high-end wheelchair athlete is able to perform at the same level or better than an able-bodied athlete, to the public the abilities of these athletes is obvious. On the other hand, an athlete that has cerebral palsy, which affects both legs and runs $100 \mathrm{~m}$ much slower than his/her able-bodied counterpart it might be difficult to see their ability.

The possibility of a re-embodiment for certain athletes with disabilities is provided through acquiring expensive sporting technologies and the process of cyborgification. The potential economic exclusion makes ineligible much of the world's population of potential Paralympians. In elite sport for the disabled, there are increasing numbers of athletes with mechanical, artificially designed bodies creating new sporting potential. These athletes are the most celebrated in part because the sport for the disabled movement developed around them. The technology they use has the capacity to 'normalise' their bodies, and in so doing produces 'sporting cyborgs'. These athletes are celebrated both inside and increasingly outside the Paralympic movement because they increase its marketability and increase the public's awareness of the ability of certain impairment groups that compete in sport. A technocentric ideology has led to this process of cyborgification that is celebrated within Paralympic sport and has made celebrities of the athletes who are successful in using the state of the art movement technologies to achieve super performances (Howe, 2008a, 2011). Such elevated status of handpicked cyborgs can be problematic for the communities of impaired individuals who can never achieve such a position. As Kama argues:

(w)ell-known, successful disabled people are put on a pedestal for their demonstrated ability to triumph. This triumph is used to validate the disabled individual and to alter societal perceptions. Consequently, the wish to see disabled who 'have done it' is particularly intense while the pitiful disabled trigger antipathy because they reproduce and reinforce disabled people's inferior positionality and exclusion (Kama, 2004: p. 447).

The celebration of the cyborg supercrip, that is manifest in the technological immersed bodies of the best wheelchair and prosthetic wearing athletes, is good for the individuals placed on the pedestal but may lead to the (dis)empowerment of other athletes with impairment who cannot take advantage of the explicit use of technology. Ultimately the Paralympics risk becoming a show of technology, rather than a show of athleticism, leaving behind those who cannot either afford or use performance-enhancing technology. Technological advancement in relation to Paralympic sport is not dissimilar to other changes in society; it is clearly a mixed blessing. Technology empowers some while leaving the status of others at best unaltered and at worst increasing their liminality. While Haraway (1991) believes that cyborgization can bring more people into the fold of the 'humanist subject', or maybe the whole notion of the subject has to be reformulated. It is clear from the Paralympic movement, with its celebration of cyborg supercrips that equality of humanity is a long way from being achievable.

\section{References}

Berger, R.J. (2004). Pushing forward: Disability, basketball, and me. Qualitative Inquiry, 10, 794-810.

Berger, R.J. (2008). Disability and the dedicated wheelchair athlete: Beyond the "supercrip" critique. Journal of Contemporary Ethnography, 37(6), 647-678.

Burkett, B. (2010). Technology in Paralympic sport: Performance enhancement or essential for. British Journal of Sports Medicine, 44, 215-220.

Butryn, T.M. (2002). Cyborg horizons: Sport and the ethics of self-technologization. In A. Miah \& S. Easson (Eds.), Sport, technology: History, philosophy, and policy (pp. 111-134). Oxford: Elsevier Science.

Butryn, T.M. (2003). Posthuman podiums: Cyborg narratives of elite track and field athletes. Sociology of Sport Journal, 20, 17-39.

Charles, J.M. (1998). Technology and the body of knowledge. Quest, 50, 379-388.

Cole, C.L. (1993). Resisting the canon: Feminist cultural studies, sport, and technologies of the body. Journal of Sport and Social Issues, 17, 77-97.

Cole, C.L. (1998). Addiction, exercise, and cyborgs: Technologies and deviant bodies. In G. Rail (Ed.) Sport and postmodern times (pp. 261-275). Albany: State University of New York Press.

Csordas, T. (1994). Embodiment and experience: The existential ground of culture and self. Cambridge: Cambridge University Press.

Davis, R, \& Cooper, R. (1999). Technology for disabilities. British Medical Journal, 13, 1-4.

DePauw, K.P. (1997). The (in)visibility of disability: Cultural contexts and "sporting bodies." Quest, 49(4), 416-430.

DesGroseillers, J.-P., Desjardins, J.-P., Germain, J.-P., \& Krol, A. L. (1978). Dermatologic problems in amputees. Canadian Medical Association Journal, 118, 535-537. 
Haller, B. (2000). If they limp, they lead? News representations and the hierarchy of disability images. In D.O. Braithwaite, \& T.L. Thompson (Eds.), Handbook of communication and people with disabilities : Research and application (pp. 273-288). Mahwah, N.J.: Lawrence Erlbaum Associates, Publishers.

Haraway, D.J. (1991). Simians, cyborgs, and women: The reinvention of nature. London: Routledge.

Hoberman, J. (1992). Mortal engines: The science of human performance and the dehumanization of sport. Oxford: The Free Press.

Howe, P.D. (2006). The role of injury in the organization of paralympic sport. In S. Loland, B. Skirstad, \& I. Waddington (Eds.), Pain and injury in sport: Social and ethical analysis (pp. 211-225). London: Routledge.

Howe, P.D. (2007). Integration of Paralympic athletes into athletics Canada. International Journal of Canadian Studies, 35, 134-150.

Howe, P.D. (2008a). The cultural politics of the Paralympic movement: Through the anthropological Lens. London: Routledge.

Howe, P.D. (2008b). The tail is wagging the dog: classification and the paralympic movement. Ethnography, 9(4): 499-518.

Howe, P.D. (2011). Cyborg and supercrip: The Paralympics technology and the (dis) empowerment of disabled athletes. Sociology, 45(5), 868-882.

Howe, P.D., \& Jones, C. (2006). Classification of disabled athletes: (Dis)empowering the Paralympic practice community. Sociology of Sport Journal, 23, 29-46.

Howe, P.D., \& Parker, A. (2012). Celebrating imperfection: Sport, disability and celebrity culture. Celebrity Studies, 3(3), 270-282.

Hudson, E. (2016). Should 'blade jumper' Markus Rehm be allowed in the Olympics? BBC Sport. http://www.bbc.co. $\mathrm{uk} / \mathrm{sport} /$ athletics $/ 35568770$.

Hughes, B. (2000). Medicine and the aesthetic invalidation of disabled people. Disability and Society, 4, 555-568.

Hunt-Grubbe, C. (2007). The blade runner generation. London: The Sunday Times. http://timesonline.co.uk/tol/life/_and style/health/article2079637.ece?print=yes.

Jones, C, \& Howe P.D. (2005). Conceptual boundaries of sport for the disabled: Classification and athletic performance. Journal of Philosophy of Sport, 32, 133-146.

Iwakuma, M. (2002). The body as embodiment: An investigation of the body by Merleau-Ponty. In M. Corker, \& T. Shakespeare (Eds.), Disability/postmodernity: Embodying disability theory (pp. 76-87). London: Continuum.

Jönsson, K. (2010). Sport beyond gender and the emergence of cyborg athletes. Sport in Society, 13(2), 249-259.

Kama, A. (2004). Supercrips versus the pitiful handicapped: Reception of disabling images by disabled audience members. Communications, 29(4), 447-466.

Kelso, P. (2012). Oscar Pistorius knocked out of London 2012 Olympics but his achievements will resound for years to come.
The Telegraph. http://www.telegraph.co.uk/sport/olym pics/athletics/9454624/Oscar-Pistorius-knocked-out-of-Lon don-2012-Olympics-but-his-achievements-will-resound-foryears-to-come.html.

Keogh, J.W.L. (2011). Paralympic sport: An emerging area for research and consultancy in sports biomechanics. Sports Biomechanics, 10(3), 234-253.

MacIntyre, A. (1999). Dependent rational animals: Why human beings need the virtues. Chicago: Open Court.

Mastro, J.V.M., Burton, A.W., Rosendahl, M., \& Sherrill, C. (1996). Attitudes of elite athletes with impairments toward one another: A hierarchy of preference. Adapted Physical Activity Quarterly, 13(2), 197-210.

Merleau-Ponty, M. (1962). Phenomenology of perception (Colin Smith, Trans.). London: Routledge (Original work published 1945).

Morrissey, R. (2008). Fast-moving technology: Prosthetics, physical ability merging in a blur. Chicago Tribune. http://dispatch.com/live/contentbe/dispatch/2008/02/03/ 20080203-C11.

Mott, S. (2000). Impaired logic keeps heroes off the stage. London: The Daily Telegraph.

Murphy, R.F. (1990). The body silent. New York: W.W. Norton \& Company, Inc.

Rossi, L.F.A. (1974). Rehabilitation following below-knee amputation. Proceeds of the Royal Society of Medicine, 67, 37-38.

Schell, L.A., \& Rodriguez, S. (2001). Subverting bodies/ ambivalent representations: Media analysis of Paralympian, Hope Lewellen. Sociology of Sport Journal, 18, 127-135.

Seymour, W. (1998). Remaking the body: Rehabilitation and change. London: Routledge.

Sherrill, C. (1999). Disability sport and classification theory: A new era. Adapted Physical Activity Quarterly, 16, 206-215.

Sherrill, C., \& Williams, T. (1996). Disability and sport: Psychosocial perspectives on inclusion, integration and participation. Sport Science Review, 1, 42-64.

Shogun, D. (1998). The social construction of disability: The impact of statistics and technology. Adapted Physical Activity Quarterly, 15, 269-277.

Silva, C. F., \& Howe, P.D. (2012). The [In]Validity of supercrip representation of Paralympic athletes. Journal for Sport and Social Issues, 36(2), 174-194.

Swartz, L., \& Watermayer, B. (2008). Cyborg anxiety: Oscar Pistorius and the boundaries of what it means to be human. Disability and Society, 23(2), 187-190.

Tuscher, A. (2016). Paralympic Champion hopes taking on Greg Rutherford leads to Olympic ticket. The Guardian. http:// www.theguardian.com/sport/2016/jan/19/markus-rehmgreg-rutherford-paralympics-olympics-rio.

Tweedy, S.M., \& Vanlandewijick, Y.C. (2009). International Paralympic Committee Position Stand-Background and scientific rationale for classification in Paralympic Sport'. British Journal of Sports Medicine. Online, 10, 29.

Cite this article as: Howe PD \& Silva CF (2017) The cyborgification of paralympic sport. Mov Sport Sci/Sci Mot, 97, 17-25 